\title{
Sensitivity to Electromagnetic Stimuli: Entwined Histories of Wireless Signals and Plant Ecologies
}

\author{
Rahul Mukherjee ${ }^{a}$ \\ Keywords: biophysics, plant sensing, wireless, environmental media, electromagnetic fields \\ https://doi.org/10.1525/001c.13523
}

Environmental media scholarship, over the last decade, has increasingly focused on the myriad entanglements, intertwinements, and co-constitutions of media and environment. These range from films depicting environmental issues and practices to media technologies being manufactured from environmental matter, such as minerals mined from the earth (Starosielski and Walker 2016; Parikka 2015). To many such pairings discussed in the inaugural stream of Media+Environment, one could add the study of the environmental health effects of mobile phones and media, and, more specifically, how electrosensitives are wary of wireless media signals and infrastructures-in their 2G, 3G, 4G, and now $5 \mathrm{G}$ avatars.

Electrosensitives - people who suffer from electromagnetic hypersensitivity - are hypersensitive to the electromagnetic fields produced by cell phones, cell towers, and Wi-Fi routers. They complain of dizziness, memory loss, sleeplessness, irritability, and muscular pain. Prevailing biomedical knowledge seems to suggest that electrosensitivity is an "impossible bodily state," but some other researchers note that it should rather be considered an "undone science" (Murphy 2000; Hess 2016). Delivering wireless services and maintaining public health are both crucial, and therefore it is not surprising that wireless service providers and affected communities often end up battling one another over the introduction of $5 \mathrm{G}$ (fifth-generation) wireless technologies, which are all the rage now. Cellular service providers tout $5 \mathrm{G}$ as the next-generation tech that will cut latency periods, provide seamless streaming as never before, and make augmented reality and the Internet of Things more fun and part of everyday "smart" lives. Some suggest caution noting that $5 \mathrm{G}$ could spark global trade and security disputes, and public health scholars remain skeptical about whether the radio frequencies emitted by $5 \mathrm{G}$ antennas are indeed safe (see Mattern 2019; Moskowitz 2019).

In this short piece, I propose a more circuitous route to understanding how wireless technology and the environment are related. Such an approach is not focused just on infrastructures that support $4 \mathrm{G}$ or $5 \mathrm{G}$ wireless media, nor

\footnotetext{
a Rahul Mukherjee is Dick Wolf Associate Professor of Television and New Media at the University of Pennsylvania. He recently published his first monograph: Radiant Infrastructures: Media, Environment, and Cultures of Uncertainty (Duke University Press 2020). A former Sustainable Futures fellow at the Society for the Humanities, Cornell University, Mukherjee has published widely in the fields of digital media and environmental media. Mukherjee's work on chronic toxicity, ruins, telecom infrastructures, and mobile digital practices can be found in journals such as Media, Culture \& Society, Journal of Visual Culture, New Media \& Society, and Science, Technology, and Human Values.
} 
is it exclusively concerned with environmentalism around the issue of electrosensitivity and the various radiation-detection and citizen sensing practices such environmentalism entails (Gabrys 2016; Mukherjee 2020). Rather, I try to find a historically, culturally, and phenomenologically nuanced epistemology of wireless technology and to see how it is intermeshed with experiments in biophysics, specific philosophies of vitalism and monism, and particular strands of feminist technoscience. I will begin with the work of biophysicist Jagadish Chandra Bose, who in the last decade of the nineteenth century began manufacturing wireless devices operating in the millimeter range to conduct scientific experiments on plant sensitivity. Some of today's $5 \mathrm{G}$ wireless waves operate in the same millimeter-wave band-a coveted highfrequency spectrum-as Bose's scientific apparatus (Rappaport, Roh, and Cheun 2014). ${ }^{1}$

In the usual media history, Bose's work is often referenced in a footnote stating that he, not Guglielmo Marconi, was the first inventor of the radio wave receiver/detector. Bose never patented his radio-wave-emitting instruments and, unlike Marconi, never pursued ways of promoting radio as commercial broadcasting equipment (Shepherd 2012; Roy 2018). At a Calcutta town hall in 1895 , Bose used a spark-gap transmitter to send a $60 \mathrm{GHz}$ signal through three walls and the body of the region's lieutenant governor to a funnel-shaped horn antenna and detector twenty-three meters away (Rappaport, Roh, and Cheun 2014). Bose's devices were scientific instruments, meant to be used for experimenting on plants so as to ascertain how they responded to external stimuli. This is a history I will seek to further unravel, but first one needs to go beyond the narrow topic of who invented radio.

Bose's ability to bring physics and biology together to understand bodily (plant, animal, human) sensitivities to electromagnetic frequencies has so far received very little attention in environmental media scholarship. It is in this research direction where, I believe, more ecocritical work is required because it has repercussions for how environmental media scholars think about multispecies relationalities and about the human body immersed in datadriven information environments. Bose's work, in the late nineteenth-century colonial period, demonstrated how incredibly sensitive plants were to external electromagnetic stimuli and therefore questioned human exceptionalism and opposed the ways humans tended to wrongfully consider plants as passive and bereft of movement (Myers 2015).

\footnotetext{
1 Different $5 G$ wireless technologies are being deployed in different countries, some which do not use millimeter waves, and some which use both millimeter waves and microwaves. Some experts believe that millimeter waves could be more widely used in $5 \mathrm{G}$ transmission in the near future. For more, refer to Alex Hern, "How baseless fears over 5 G rollout created a health scare." The Guardian, Feb 26, 2019. Available: https://www.theguardian.com/technology/2019/jul/26/how-baseless-fears-over-5g-rollout-created-a-health-scare. Also, while Bose did make millimeter wave apparatuses, he also worked on microwave instruments.
} 


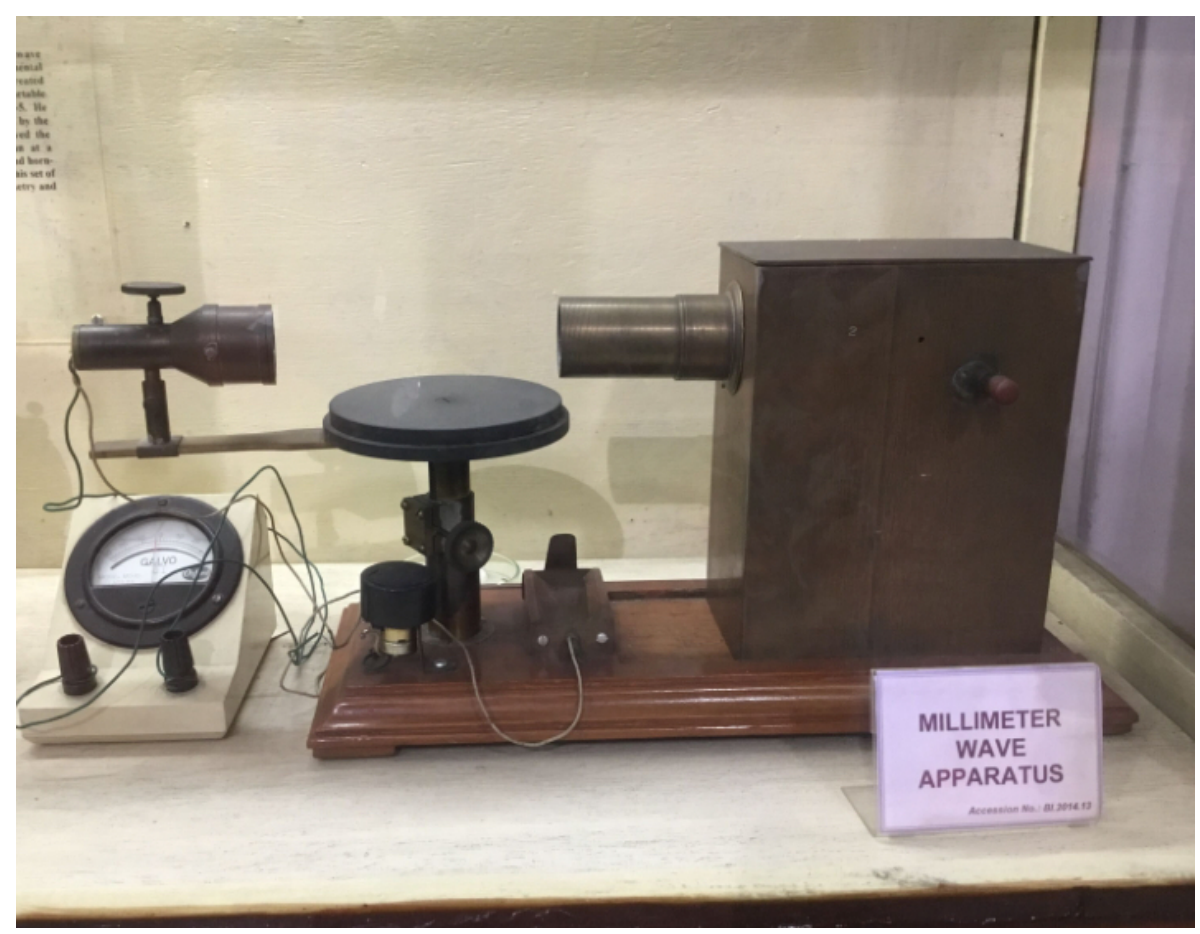

Figure 1a: Millimeter-wave apparatus manufactured by J. C. Bose. Photographed by the author at the Bose Museum, Kolkata.

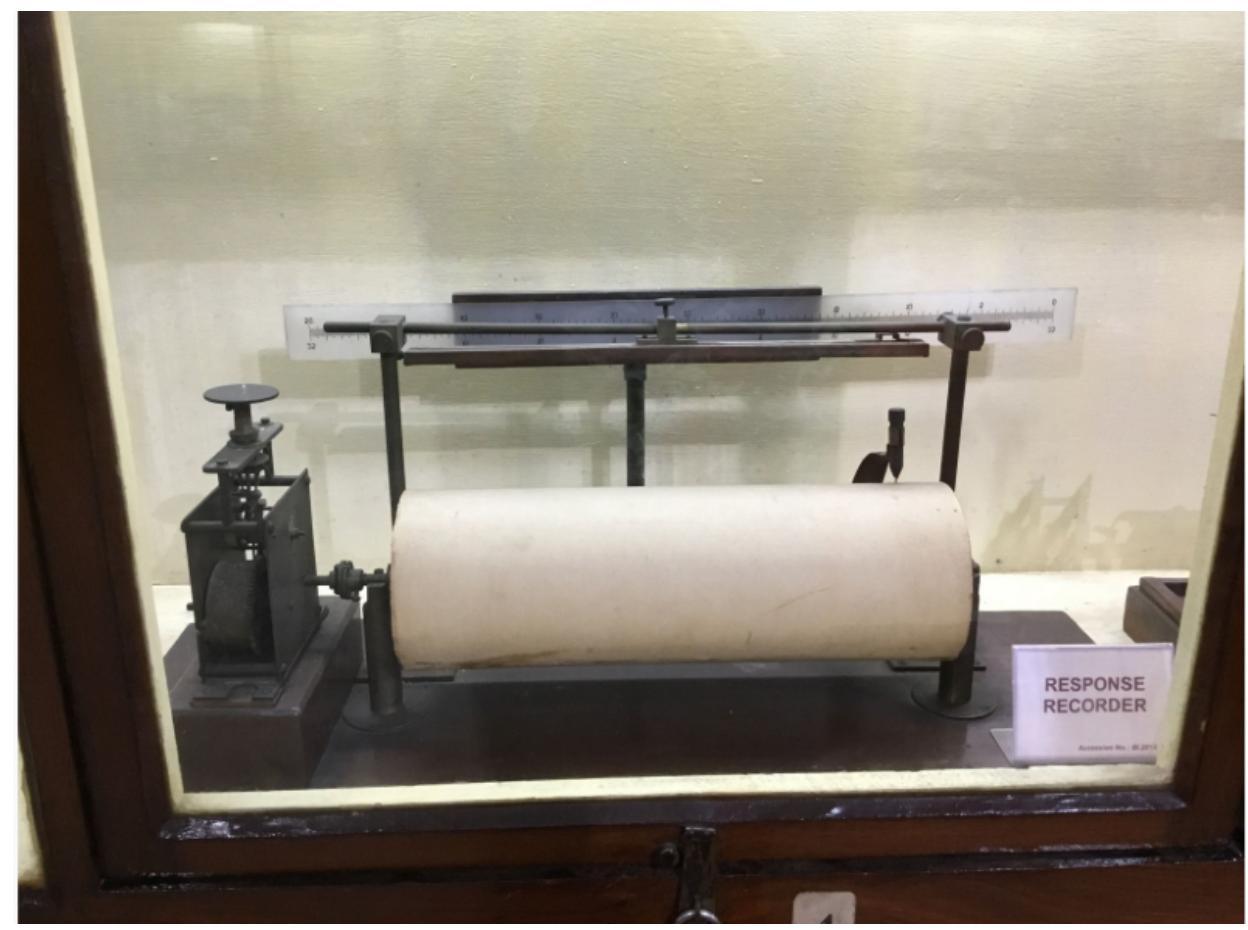

Figure 1b: Response recorder manufactured by J. C. Bose. Photographed by the author at the Bose Museum, Kolkata.

Bose invented and used "dielectric lenses, a horn antenna ('funnel'), wave guides, and polarisers" (Shepherd 2012) to measure very small movements of plants (see figure 1ab). His work creating millimeter wave and microwave technologies from 1894 to 1899 was highly regarded by many physicists 
including Bose's former teacher Lord Rayleigh at Cambridge. Bose was extending the work started by James Clerk Maxwell and other scientists on understandings of electromagnetic fields. Today, the $30-300 \mathrm{GHz}$ millimeterwave band (which Bose's devices operated in) is being used by 5G wireless networks (Rappaport, Roh, and Cheun 2014). Yet again, like the late nineteenth-century debates regarding plant sensitivity to millimeter waves, today there is controversy about the electrosensitivity of human beings to waves emitted by $5 \mathrm{G}$ cellular antennae. ${ }^{2}$

What adds to the anxiety of electrosensitives and to the indifference of many who consider wireless signals to be benign is that these signals are invisible and impalpable. The electrosensitives claim to bear the effects of these signals on their bodies, and hence the question of "sensitivity" to "invisible" electromagnetic radiation is central. This aspect was not lost on Bose while he was doing his experiments in the early twentieth century. In a lecture Bose delivered in 1911, the scientist noted that he was using the invisible (to human senses) light of electromagnetic rays to shine light on the small movements of plants, on their "unvoiced life." In his own words: "Can anything appeal more to the imagination than the fact that we can detect the peculiarities in the internal molecular structure of an opaque body by means of light that is itself invisible?" (Bose 1911). The small movements of plants, their voices, were part of electromagnetic interferences.

Based on his experiments, Bose characterizes human sense organs as acting like "antennae" responsive to wireless signals, thereby arguing that impulses within the body vibrate and interfere with electromagnetic fields. At another point, Bose notes that his findings clearly suggest that plants are sensitive to invisible electromagnetic rays, which leads him to intuit that plants have "nervous" (nerve) impulses and not merely automatic biomechanical movements (Bose 1929, 1926). Bose's formulation can be read as follows: response to stimulation is interpreted as proving the existence of nervous pulsatory impulses, which in turn suggests consciousness. He cites Henri Bergson to suggest that an organism need not have a central nervous system to have consciousness or sentience, arguing that plants have a more distributed nerve network:

The philosopher Bergson says that it is by no means assured that [a] highly complex brain is indispensable to consciousness. The lower we go in the animal series, the more the nerve centers are simplified and separated from each other. If then, at the top

2 The millimeter band had long been ignored by the telecom industry, the initial RF circuit and antenna equipment was unsophisticated and costly, and it took a while for wireless science to come up with better designs for antennae so that $5 \mathrm{G}$ wireless technology could be commercially rolled out (Rappaport, Roh, and Cheun 2014). What bothers electrosensitives and public health scholars is that while there have been some studies of the potential harmful effects of $2 \mathrm{G}$ and $3 \mathrm{G}$ wireless signals, both $4 \mathrm{G}$ and $5 \mathrm{G}$ have been introduced for public consumption without significant studies of their impact on health and environment (Moskowitz 2019). 
of the scale of living beings, consciousness is attached to very complicated centers, must we suppose that it accompanies the nervous system down its whole descent. (Bose 1929)

In his book Creative Evolution, Bergson $(1911,109)$ noted that consciousness does not necessarily involve as a "necessary condition the presence of a nervous system," which certainly helps Bose make the case that consciousness does not require developed brains and can exist in organisms with distributed nerve centers. Such statements by Bose reveal what some considered his obsession with plant sensitivity, and very soon they became a matter of contention. Many scientists were astonished by Bose's (1927) statements (in an essay titled "Plant Autographs") that "plants have a voice" and that "trees grieved." Many who disagreed with these views suggested that Bose was under the influence of scriptural notions of "monism," which made him believe in the unity of plant, animal, human, and metal matter (Brown 2016). Consider this excerpt from a lecture by Bose:

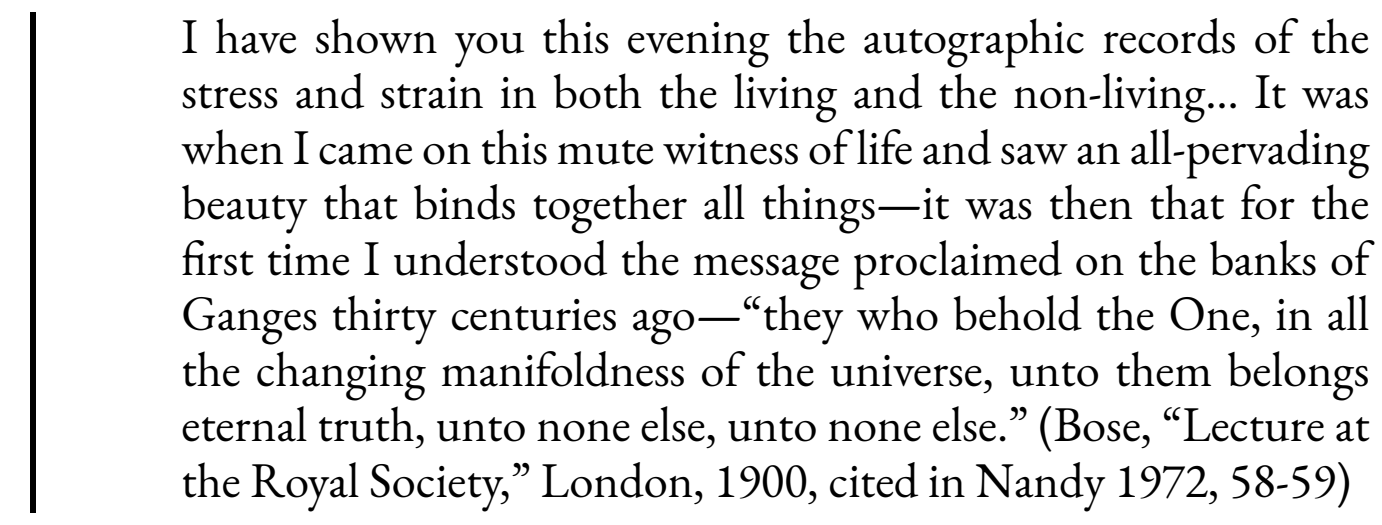

Bose mentions this unity of life thesis at the peroration of his scientific lecture at the Royal Society. After having demonstrated the recorded traces of plant sensitivity on his delicate instruments, Bose chose to cite Hindu scripture to explain how his experiments validated a monistic notion, where a unity of life across biotic and abiotic life, animate and inanimate matter, was being suggested. Exhibiting cultural nationalism, Bose mixed science and religion in a provocative anticolonial stance. Furthermore, his phenomenological understandings of plant sensitivity were shaped by his cultural upbringing in the Bengal Province of British India. Bose believed that plant, animal, and human matter were all powered by mahashakti, which is Sanskrit/Bangla for "ultimate energy" and has some resonances with "ether" in its all-encompassing quality. Bose thought that wireless signals were interfering with this mabashakti. His claim that electromagnetic energy ran through both living and non-living entities and his notions of "vitalistic monism" suggest a media system, akin to organicist (process) philosophy where plants and metals become communicating entities (mediating through electromagnetic pulses) alongside humans and animals (Shepherd 2012). Discussing Bose's writings, Ashis Nandy $(1972,40)$ notes that Bose's characterization of mabashakti for "ultimate power" is "represented by the dominant mother-deities of Bengal." 
Here, Bose is connecting the electrical/electromagnetic signaling across human, animal, and plant bodies to divine forms of energy. Bose's scientific experiments and writings therefore suggest that phenomenological experiences and cultural contexts (Bose's Brahmo and Vedantic leanings) mutually shape one another.

Even as there remains a cultural-religious angle to Bose's experiments and ideas, his almost poetic accounts of his experiments measuring movement in plants are important for contemporary plant-studies scholars, who insist that "plants move, they move other things, they move people, and they are themselves being moved around" (Thorsen 2017, 11). Molecular biologist and feminist science studies scholar Deboleena Roy (2018) emphasizes Bose's claim that the living and the nonliving are capable of "response" (and not mere "reaction"). ${ }^{3}$ Bose's use of electrical/electromagnetic activity to demonstrate that physiological activity extends beyond the human - to not only animals, plants, and microorganisms but even rocks and metals-suggests a certain ontology and ethics of encounter that helps Roy "reimagine feminist encounters with biology" (59). For Roy, Bose's demonstration and claim of a physiology of response provides a pathway to "cultivating an openness to nonhuman becomings and changefulness" (60). Today's feminist technoscience studies scholars thus view Bose's work as influencing interdisciplinary inquiries in bioart, microphysiology, and plant neurobiology (Cinti 2011; Hustak and Myers 2012; Roy 2018).

There is much to be gained from taking Bose's inquiries into plant life along affirmative trajectories and lines of flight. That said, some caveats about the way Bose's work is interpreted need to be considered. Scholars quarrel over whether his monistic thesis suggests that there is continuity across plant and animal life (and living and nonliving entities), or whether he simply demonstrated that there is continuity in responses to electromagnetic stimuli across plants and animals (Brown 2016). Furthermore, Bose seems to slide easily from demonstrations of plant response to electromagnetic stimuli to claims about plant consciousness and sentience. Debates about plant intelligence continue among plant neurobiologists as can be read in the papers published in the journal Plant Signaling and Behavior. Several molecular biologists that anthropologist Natasha Myers (2015) interviewed were open to discussing "plant sensing" but not "plant feeling." Myers notes that "plant sensing" could mean how "plants sense, perceive, and respond to environments" (35). "Plant feeling" could at some level also mean "plant sensing," in the way plants "feel out their world," but such semantic flexibility is allowed only to a limited extent. Molecular biologists did not want to converse about "plant feeling" if the term began to connote vegetal emotions and plant intelligibility. 
Bose's experiments and their uptake in mobile media studies and feminist technoscience studies gesture to an environmental media theory that is committed to studying the entanglements of media, body, and environment through multisensory techniques attending to human (and nonhuman) perceptions, sensations, and experiences of electromagnetic signals. ${ }^{4}$ What becomes apparent from studying plant sensitivity to electromagnetic stimuli is that plants sense in ways that humans do not. Going beyond the five human senses, plants interact with environmental changes, mediating between sunlight in the sky and minerals deep inside the soil. Studying wireless media should not be just about celebrating the technocratic possibilities of the Internet of Things, nor should it be limited to the infrastructures that support signal traffic. As I have argued (based on my ongoing research), there is a more expansive historical detour, a botanical history of wireless media, which imbricates mobile media technologies, radio waves, biophysics, and ideas of vitalistic monism and process philosophy.

\section{Author's Note}

Thanks to Diksha Dhar for research assistance in Kolkata and am grateful to $M+E$ journal editors for encouraging me to write this short essay.

This is an open-access article distributed under the terms of the Creative Commons Attribution 4.0 International License (CCBY-4.0). View this license's legal deed at http://creativecommons.org/licenses/ by/4.0 and legal code at http://creativecommons.org/licenses/by/4.0/legalcode for more information.

\footnotetext{
4 Plants have been mediated to make human observers perceive and discern the awareness and movements that plants are capable of, and Bose's experiments can be seen as one kind of such mediation. As Teresa Castro (2019) writes, today's "sensitive" or "sentient" plant is "necessarily a post-natural mediated plant," a plant that humans are accessing through various audio-visual technologies.
} 


\section{REFERENCES}

Bergson, Henri. 1911. Creative Evolution. New York: Henry Holt and Company.

Bose, Jagadish Chandra. 1911. "Literature and Science." Delivered as the President of Bengal Literary Congress at Mymensingh, April 14.

- - . 1926. The Nervous Mechanism of Plants . London: Longmans Green and Co., Ltd. https://doi.org/10.5962/bhl.title.139322.

- - 1927. Plant Autographs and Their Revelation. London: Longmans Green and Co., Ltd. https://doi.org/10.5962/bhl.title.139749.

_-_. 1929. "Is the Plant a Sentient Being." Century Magazine, February 1929.

Brown, Christopher Mackenzie. 2016. “Jagadish Chandra Bose and Vedantic Science.” In Science and Religion: East and West, edited by Yiftach Fehige, 104-22. London and New York: Routledge.

Castro, Teresa. 2019. “The Mediated Plant.” E-Flux 102 (September). https://www.e-flux.com/ journal/102/283819/the-mediated-plant/.

Cinti, Laura. 2011. "The Sensorial Invisibility of Plants: An Interdisciplinary Inquiry through Bio Art and Plant Neurobiology.” Thesis. Center for Advanced Biomedical Imaging University College London.

Gabrys, Jennifer. 2016. Program Earth: Environmental Sensing Technology and the Making of a Computational Planet. Minneapolis: University of Minnesota Press. https://doi.org/10.5749/ minnesota/9780816693122.001.0001.

Hess, David J. 2016. Undone Science: Social Movements, Mobilized Publics, and Industrial Transitions. Cambridge, MA: MIT Press. https://doi.org/10.7551/mitpress/ 9780262035132.001.0001.

Hustak, Carla, and Natasha Myers. 2012. "Involutionary Momentum: Affective Ecologies and the Sciences of Plant/Insect Encounters." Differences: A Journal of Feminist Cultural Studies 23 (3): 74-118. https://doi.org/10.1215/10407391-1892907.

Mattern, Shannon. 2019. "Networked Dream Worlds: Is 5g Solving Real, Pressing Problems or Merely Creating New Ones?” Real Life Magazine, July 8, 2019. https://reallifemag.com/ networked-dream-worlds/.

Moskowitz, Joel. 2019. "We Have No Reason to Believe 5G Is Safe." Scientific American, October 17, 2019. https://blogs.scientificamerican.com/observations/we-have-no-reason-to-believe-5g-issafe/?fbclid=IwAR1ubea0PTG2t8F_adla-XzEd7f7jNDu4Hz6Ym06k0rv5ccCiccNOt3nM8.

Mukherjee, Rahul. 2020. Radiant Infrastructures: Media, Environment, and Cultures of Uncertainty. Durham: Duke University Press. https://doi.org/10.1215/9781478009016.

Murphy, Michelle. 2000. “The 'Elsewhere within Here' and Environmental Illness; or, How to Build Yourself a Body in a Safe Space.” Configurations 8 (1): 87-120. https://doi.org/10.1353/ con.2000.0006.

Myers, Natasha. 2015. “Conversations on Plant Sensing: Notes from the Field.” NatureCulture 3: $35-66$.

Nandy, Ashis. 1972. "Defiance and Conformity in Science: The Identity of Jagadish Chandra Bose.” Science Studies 2 (1): 31-85. https://doi.org/10.1177/030631277200200102. 
Parikka, Jussi. 2015. A Geology of Media. Minneapolis: University of Minnesota Press. https://doi.org/10.5749/minnesota/9780816695515.001.0001.

Rappaport, Theodore, Wonil Roh, and Keungwhoon Cheun. 2014. "Smart Antennas Could Open Up New Spectrum for 5G.” IEEE Spectrum, August 28, 2014. https://spectrum.ieee.org/telecom/ wireless/smart-antennas-could-open-up-new-spectrum-for-5g.

Roy, Deboleena. 2018. Molecular Feminisms: Biology, Becomings, and Life in the Lab. Seattle: University of Washington Press.

Shepherd, Virginia A. 2012. "At the Roots of Plant Neurobiology: A Brief History of the Biophysical Research of JC Bose." Science and Culture 78 (May-June): 3-43. https://doi.org/ 10.1007/978-3-642-29119-7_1.

Starosielski, Nicole, and Janet Walker, eds. 2016. Sustainable Media: Critical Approaches to Media and Environment. London and NYC: Routledge. https://doi.org/10.4324/9781315794877.

Thorsen, Line Marie. 2017. “Introduction: Moving Plants." In Moving Plants, edited by Line Marie Thorsen, 11-15. Næstved: Narayana Press. 